\title{
Smoking, Respiratory Diseases and Endothelial Dysfunction
}

\author{
Vera Nevzorova, Tatiana Brodskaya and \\ Natalia Zakharchuk \\ Additional information is available at the end of the chapter
}

http://dx.doi.org/10.5772/intechopen.73555

\begin{abstract}
Vascular endothelium actively participates in inflammatory reactions in the majority of chronic respiratory diseases. Smoking is a major risk factor for bronchopulmonary diseases, and it plays an important role in endothelial dysfunction development. Some experiments prove that aggressive pollutants of tobacco smoke (benzopyrene, peroxynitrite, acrolein, cyanides, peroxides, etc.) can cause direct damage to endothelial cells due to expression of adhesion molecules on their surface and intensification of lipid peroxidation. In turn, oxidized lipoproteins in the tunica intima of the vessel work as attractants for chemotaxis of leukocytes and monocytes that start to produce pro-inflammatory cytokines in big amounts. These processes trigger systemic inflammatory response that leads to irreversible thickening of the vessel walls and deterioration of their mechanical properties. Chronic exposure to tobacco smoke and the products of combustion of tobacco leads to chronic system inflammatory reaction, oxidative stress, endothelial dysfunction and morpho-functional damage of target organs. Nowadays, the connection between chronic obstructive pulmonary disease (COPD) and some cardiovascular and cerebrovascular diseases has been well established. Studying the mechanisms of endothelial dysfunction in brain blood vessels of patients with smoking habits and COPD can be very important for preventing acute vascular events.
\end{abstract}

Keywords: endothelium, endothelial dysfunction, cardiovascular system, cerebral vessels, smoking, respiratory diseases, COPD

\section{Introduction}

Vascular endothelium initiates and actively participates in inflammatory reactions in the majority of chronic respiratory diseases. Endothelial dysfunction (ED) that develops as clinically 
manifested disruptions of endothelium-dependent vasomotor reactions on local and systemic levels related with inflammation of different genesis should be regarded as a major segment of the cardiorespiratory continuum. Endothelium can autonomously produce at least 20 biologically active substances that are synthesized and released depending on current functional requirements. Endothelium functions create a balance of regulatory substances that determine the whole operation of interaction and control system (Figure 1). They include factors that are responsible for contraction and relaxation of smooth muscles in vessel walls, coagulation and fibrinolysis, control of cell proliferation and apoptosis, regulating the reaction to foreign substances and facilitating interaction with lymph vessels and drainage.

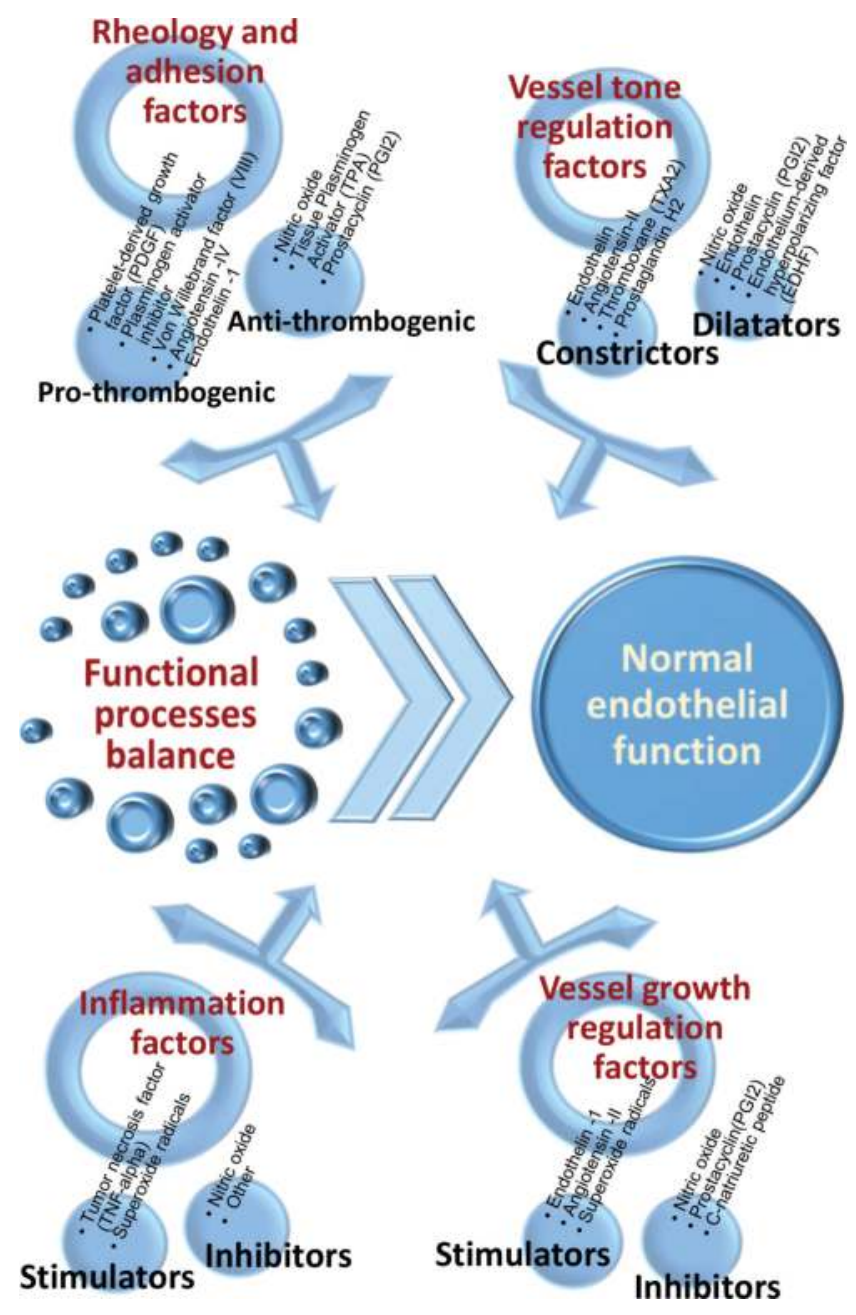

Figure 1. Functional processes balance in normal endothelial function. 
Today there is a substantial amount of evidence proving the endothelium involvement in development of local and systemic damage from tobacco smoke that is an indisputable cause of chronic respiratory diseases, such as chronic obstructive pulmonary disease (COPD), some phenotypes of asthma, idiopathic pulmonary fibrosis and so on $[2,7,8,20]$. The correlation between the intensity of tobacco smoking and rapid decline in lung function is a proven fact. According to $\mathrm{WHO}$, tobacco smokers experience sudden death five times more frequently than non-smokers [1]. The mechanisms of damage done to the blood vessels induced by tobacco combustion products have not been studied extensively at the moment, even though it is accepted that tobacco does not have any exclusive ways of producing vascular damage. Nicotine being the main component of tobacco smoke stimulates catecholamine release leading to stimulation of $\beta 1$ and $\beta 2$ adrenoreceptors. Nicotine induces a degradation of nitric oxide (NO) [2]. NO induces vasodilation by stimulating soluble guanylate cyclase (GC) to produce cyclic guanosine monophosphate (cGMP) [3]. Thus, nicotine causes change of reactions during vasodilatation. Apart from nicotine, tobacco smoke includes 4000 chemical substances, 100 of them having various toxic effects along with antigenic, cytotoxic, mutagenic and carcinogenic properties $[4,5]$. They are able to interfere with cellular structure and processes of intercellular signaling by stimulating apoptosis, lipid peroxidation in cellular membrane, DNA and RNA strings' rupture and mitochondrial respiratory chain disruption. Tobacco smoke components are not the only factors directly responsible for stimulating and damaging endothelium in case of respiratory diseases; there are also endogenous factors, such as cellular and non-cellular inflammation mediators, bacterial toxins, immune complexes, hypoxemia, free radicals and shear stress alteration in endothelium [6-12].

In general, the sequence of events altering functional properties of endothelium can be described as follows. Damaging factors (different in nature, intensity and length) activate and/or damage endothelium gradually exhausting its compensation abilities and leading to abnormal (altered) response to the same damaging factors and even to regular stimuli. It results in prolonged vasoconstriction, higher adhesion and clotting level, weakened barrier function, intensification of cellular proliferation and some other consequences with certain clinical symptoms: vascular hypertension, swelling, vascular remodeling and so on. In addition, some effects, including those related to renin-angiotensin system and endothelial involvement in inflammation process, are both local and systemic nature.

\section{Respiratory diseases and cerebral vascular endothelial dysfunction}

According to modern conceptions, the central nervous system is an important participant in the pathogenesis of a number of chronic respiratory diseases, including those having a nicotineassociated nature. An important regulator of hemoperfusion of the brain is the vascular endothelium [8]. There are specific endothelium-dependent reactions in the arteries of the brain $[9,15]$. Cerebral autoregulation maintains constant blood flow $(\mathrm{CBF})$ through the brain in spite of changing mean arterial pressure. Autoregulation of cerebral blood flow consists of mechanoand chemoregulation. Chemoregulation is in direct correlation to the serum level of carbon dioxide and is, contrary to mechanoregulation, independent of changes in mean arterial pressure. 
Mechanoregulation depends on transmural pressure gradient and endothelial vasodilatation. Mechanoregulation has been shown to be the main supervisory mechanism of CBF. However, it is well established that endothelial vasodilatation of greater arteries is much more pronounced in cerebral vasculature than elsewhere. Proper endothelial function is of crucial importance in regulation in many vascular beds. Dysfunctional cerebral endothelium releases less endothelial NO. As a consequence, relaxation of smooth muscle cells of small arteries is disturbed. Studies in animals and humans have revealed that mechanoregulation is not compromised even in older age and pathological conditions harming endothelium. On the contrary, outcomes of many studies and clinical reports confirm the dependency of chemoregulation of CBF on vascular endothelial integrity. Reduced chemoregulation was found in patients with dysfunctional cerebral endothelium [9]. The development of cognitive disorders recognized by experts as a typical systemic manifestation of the disease remains insufficiently investigated so far in the pathogenesis of nicotine-associated respiratory diseases and in particular COPD [10, 11, 16, 17]. It has been proven that one of the manifestations of vascular dysfunction can be a violation of the regional correspondence of the blood flow, which has a significant effect on the further course of the disease $[12,13,18,19]$. According to research, a complex cascade of teratogenesis in respiratory diseases initiates acute and chronic hypoxemia and, in severe cases, hypercapnia. In turn, cerebral dysfunction in COPD can be a factor in the violation of respiratory and vasomotor reactivity in response to hypercapnia due to a decrease in the sensitivity of central chemoreceptors to it. It is known that central chemoreceptors represent up to $80 \%$ of the total chemo-sensitivity of the organism to carbon dioxide $[4,5]$. The consequence of the violation of central vasomotor control is inadequate blood supply to various areas, including the brain itself $[4,5,15]$. Not being invalidating, violations of the central nervous system significantly affect the ability to work and social activity of patients. The main consequence of the violation of brain perfusion in these patients is the violation of the integral function of the central nervous system, which results in inadequate blood supply to various areas, including the brain [5, 7, 9]. This becomes the closing link of a peculiar "vicious circle" of regional vascular dysfunctions. Figure 2 shows the place and role of functional imbalance of endothelium-dependent mechanisms in the pathogenesis of respiratory diseases.

\subsection{Effect of tobacco smoke components on vascular function}

Consequences and mechanisms of tobacco combustion products damaging vascular bed still require more research. Tobacco smoking is known to cause ED [19, 21] that has its peculiarities depending on the intensity and time of exposure as well as characteristics of the arteries. For instance, one of the crucial characteristics of cerebral blood circulation is a high level of autonomous self-regulation providing relative independence of cerebral hemodynamics from shifts in systemic circulation. Short-term exposure to tobacco smoke results in damage from its toxins on vascular endothelium and activation of sympathoadrenal system. [22]. Chronic exposure to tobacco smoke leads to a lower level of endothelial NO synthase (eNOS) activity and NO synthesis, adhesion molecules expression on the surface of endothelial cells, protein kinase C (PKC) activation and intensification of lipid peroxidation followed by persistent remodeling of the vascular wall $[23,24]$. Some experiments describe development of endothelial dysfunction of cerebral and conductance arteries in mice exposed to tobacco smoke that was characterized by significant intensification and predominance of constricting activity of 


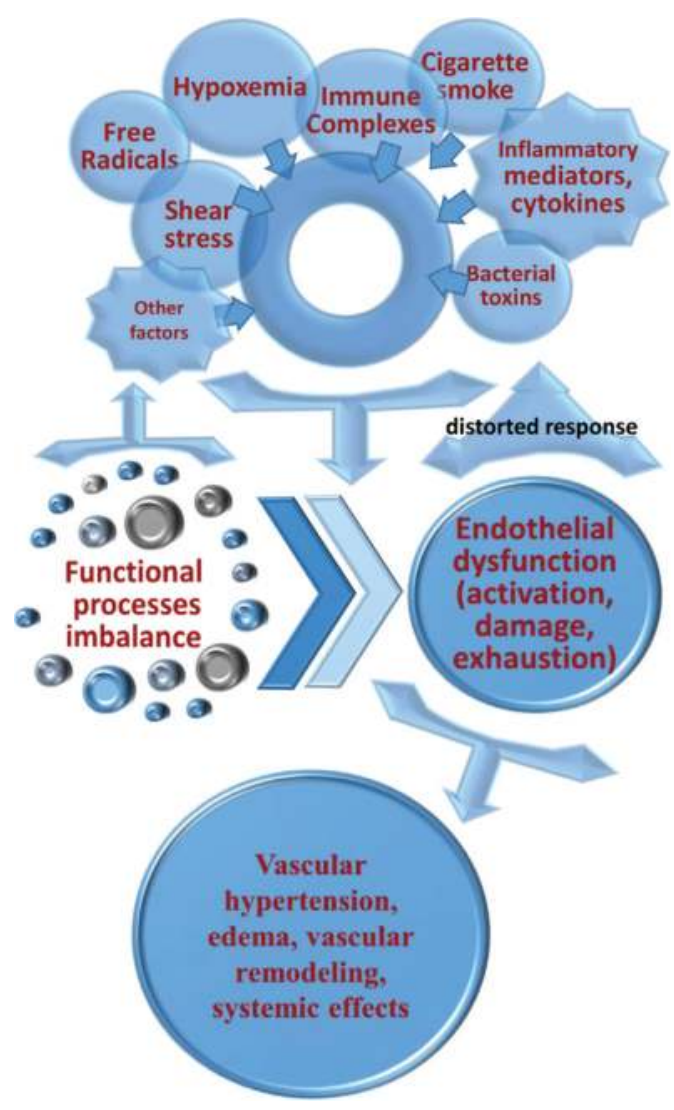

Figure 2. Functional processes imbalance due to endothelial dysfunction in respiratory diseases.

arteries, as well as abnormal reduction of cerebral arterial vasodilatory reserve along with asymmetric increase of carotid artery constriction [11, 14]. Apart from endothelial dysfunction and alterations of vasomotor reactions in response to tobacco smoking, some experiments revealed a connection between long-term exposure to tobacco smoke and irreversible changes in large arteries, such as wall thickening and deterioration of their mechanical properties [24, 25]. At the same time, smoke-exposed rats showed elevated levels of elastase and progressing degenerative changes of thoracic and abdominal aorta accompanied by a lower quality of their elastic and mechanical properties [26]. Some researches show that smoking increases risk of development of abdominal aortic aneurysm (AAA). For example, AAA growth rate was lower in those with low ankle/brachial pressure index and diabetes but higher for current smokers. No other factor (including lipids and blood pressure) was associated with AAA growth. [27]. Current smokers were 7.6 times more likely to have an AAA than non-smokers. Ex-smokers were 3.0 times more likely to have an AAA than non-smokers. Duration of smoking was significantly associated with an increased risk of AAA, and there was a clear linear dose response relationship with the duration of smoking; each year of smoking increased the relative risk of AAA by $4 \%$ [28]. 


\subsection{Carotid arteries condition in COPD depending on the smoking status}

COPD is considered to be systemic pathology with multiple extrapulmonary effects that define patients' prognosis and quality of life. Smoking plays a significant part in COPD pathogenesis. Chronic exposure to tobacco smoke works as an integral agent between topical changes of bronchopulmonary system and systemic pro-inflammatory activation with development of oxidative stress, endothelial dysfunction and progressing morphofunctional damage of target organs. Today, the connection of COPD and some cardiovascular and cerebrovascular diseases with atherosclerotic vascular damage has been proven [29, 30]. Atherosclerosis of conductance cerebral arteries also might be both the reason for chronic brain ischemia and a sign of severe alterations in brain blood circulation.

An important indicator of atherosclerosis is thickening of intima-media complex of carotid arteries and development of atherosclerotic plaques that serve as markers for high risk of developing ischemic heart disease and stroke, as shown by the data from the Cardiovascular Health Study and Rotterdam Study [31]. Implementation of different imaging methods has significantly broadened the horizons of atherosclerosis diagnostics. One of the methods is ultrasound scanning of brain vessels that has some advantages, like providing extensive information, non-invasiveness of the procedure, accessibility and relatively low cost. Also, this method allows to get information about structural characteristics of atherosclerotic plaques, velocity and spectral parameters of the blood flow [32]. Nowadays there is an ongoing search for general risk factors and development mechanisms of cardiovascular and cerebrovascular pathology in COPD.

Using transcranial Doppler ultrasound (Nicolet Companion Biomedikal, the USA), we evaluated some parameters of cerebral hemodynamics. The research included 75 COPD patients (aged $54.81 \pm 8.36$ years) who smoke. The control group consisted of 20 healthy volunteers of comparable gender and age. Using carotid duplex ultrasound (MyLab 50 Esaote, Italy), we measured intima-media thickness (IMT) of the common carotid arteries (CCA) and middle cerebral arteries (MCA). We found thickening of the intima-media complex in the majority of COPD patients who smoke (Figure 3). Apart from that, one-third of the examined patients had atherosclerotic plaques in the CCA bifurcation area and internal carotid artery mouth that led to artery stenosis in up to $22.5 \pm 4.2 \%$ of cases. Parameters of velocity are presented in Tables 1 and 2.

Some papers present convincing data on direct connection between COPD patients with carotid atherosclerosis and air flow velocity shown by spirometry [34-36]. COPD patients are more likely to have unstable atherosclerotic plaques with big lipid nuclei. These changes are visible even in patients with a mild case of COPD. Lahousse et al. have discovered that atherosclerotic plaques are very common for COPD patients in $60 \%$ of non-smoking patients and $80 \%$ of smokers [36]. Atherosclerotic plaques in case of COPD have a high risk of rupture even for patients with a very mild case of airway obstruction, while smoking only increases that risk [37]. Unstable atherosclerotic plaques with big lipid nuclei appear early in COPD and explain the doubling of mortality rates from cardiovascular diseases in this group of patients [38]. Animal tests show that systemic inflammation in COPD releases pro-inflammatory 


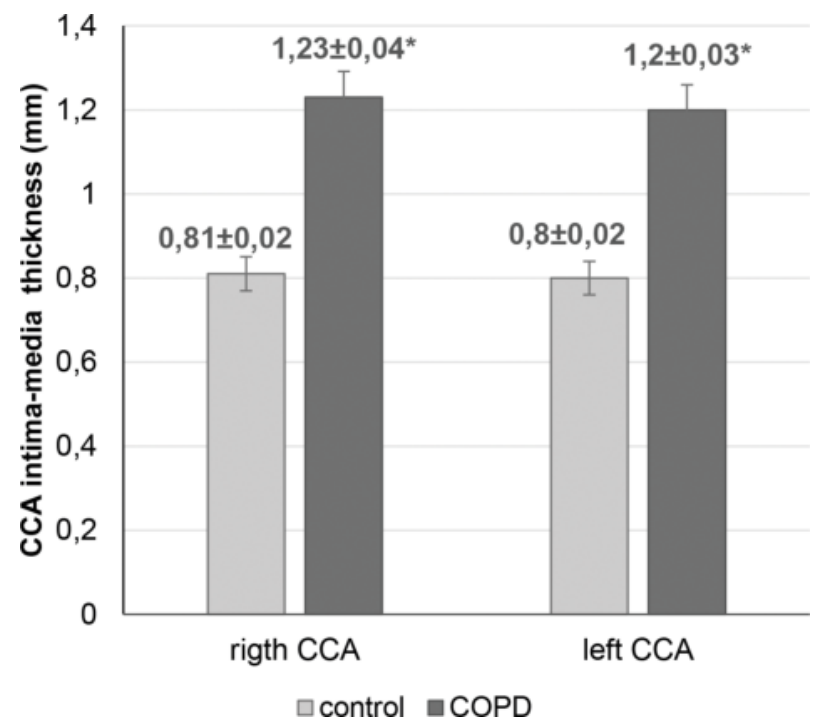

Figure 3. The thickness of the intima-media complex in the common carotid arteries in COPD patients and healthy people according to the data of ultrasound duplex scanning (mean $\pm \mathrm{SD},{ }^{*} \mathrm{p}<0.05$ in comparison with the control group; t-test analysis was used to assess the differences in the values). CCA: common carotid artery. Explanations are in the text.

mediators that facilitate inflammatory cells migration into atherosclerotic plaques, increasing the level of lipids there and thus creating unstable plaques [39].

Exposure to smoke induces a significant thickening of intima-media complex in conductance arteries, atherosclerotic plaques in the CCA bifurcation area and internal carotid artery mouth

\begin{tabular}{lll}
\hline Parameter & Control (healthy people, N = 20) & COPD and smoking (patients, N = 75) \\
\hline Peak systolic velocity in the right CCA, cm/s & $71.5 \pm 7.3$ & $53.1 \pm 5.5^{*}$ \\
Mean velocity in the right CCA, cm/s & $38.2 \pm 4.0$ & $27.4 \pm 3.1^{*}$ \\
End diastolic velocity in the right CCA, cm/s & $18.4 \pm 1.6$ & $14.9 \pm 1.5^{*}$ \\
Peak systolic velocity in the left CCA, cm/s & $72.9 \pm 8.1$ & $53.9 \pm 5.2^{*}$ \\
Mean velocity in the left CCA, cm/s & $37.9 \pm 3.9$ & $27.3 \pm 3.1^{*}$ \\
End diastolic velocity in the left CCA, cm/s & $18.8 \pm 1.7$ & $15.1 \pm 1.4^{*}$ \\
Pulsatility index in the right CCA & $2.02 \pm 0.24$ & $1.39 \pm 0.13^{*}$ \\
Pulsatility index in the left CCA & $2.04 \pm 0.25$ & $1.50 \pm 0.16^{*}$ \\
Resistance index in the right CCA & $0.75 \pm 0.04$ & $0.71 \pm 0.06$ \\
Resistance index in the left CCA & $0.74 \pm 0.05$ & $0.70 \pm 0.06$
\end{tabular}

Data are presented as mean $\pm \mathrm{SD} .{ }^{*} \mathrm{p}<0.05$ (t-test analysis was used to assess the differences in the values) in comparison with the control group. COPD is chronic obstructive pulmonary disease and CCA is common carotid artery.

Table 1. Blood flow parameters from transcranial dopplerography in the common carotid artery. 


\begin{tabular}{lll}
\hline Parameter & Control (healthy people, N = 20) & COPD and smoking (patients, N = 75) \\
\hline Peak systolic velocity in the right MCA, cm/s & $95.8 \pm 11.1$ & $91.2 \pm 10.6$ \\
Mean velocity in the right MCA, cm/s & $56.1 \pm 4.1$ & $48.2 \pm 3.2^{*}$ \\
End diastolic velocity in the right MCA, cm/s & $49.8 \pm 3.9$ & $46.7 \pm 3.0$ \\
Peak systolic velocity in the left MCA, cm/s & $93.8 \pm 9.8$ & $85.2 \pm 8.8$ \\
Mean velocity in the left MCA, cm/s & $56.0 \pm 4.6$ & $44.8 \pm 3.3^{*}$ \\
End diastolic velocity in the left MCA, cm/s & $49.2 \pm 4.0$ & $44.4 \pm 3.7$ \\
Pulsatility index in the right MCA & $0.82 \pm 0.04$ & $0.93 \pm 0.05^{*}$ \\
Pulsatility index in the left MCA & $0.81 \pm 0.04$ & $0.93 \pm 0.04^{*}$ \\
Resistance index in the right MCA & $0.47 \pm 0.03$ & $0.50 \pm 0.03$ \\
Resistance index in the left MCA & $0.46 \pm 0.03$ & $0.49 \pm 0.04$ \\
\hline
\end{tabular}

Data are presented as mean $\pm \mathrm{SD} .{ }^{*} \mathrm{p}<0.05$ (t-test analysis was used to assess the differences in the values) in comparison with the control group. COPB is chronic obstructive pulmonary disease and MCA is middle carotid artery.

Table 2. Blood flow parameters from transcranial dopplerography in the middle cerebral artery.

that leads to partial artery stenosis [33]. Long-term exposure to toxic products of tobacco combustion causes hypertrophy of smooth muscle cells, disorganization of arterial myoelastic tissue, faster lipid peroxydation leading to thickening of vessel walls, deterioration of their mechanic properties and atherogenesis $[23,40]$. It results in the lower level of arterial elasticity, excessive rigidity of vessel walls with loss of their damping properties in response to fluctuations of systemic arterial pressure and other effects of situational hemodynamic stresses, thus, increasing the risk of arterial hypertension and worsening the prognosis for the course of the disease [41].

Structural deterioration of conductance arteries causes alterations in blood flow velocity. At the same time, the resistance of peripheral vessels and elastic properties of vessel wall decrease which is indicated by lower pulsation index and, to a lesser extent, resistance index [33].

Our studies of blood flow in conductance and extracerebral arteries using transcranial dopplerography showed reduced velocity of blood flow in common carotid arteries and medial cerebral arteries (Tables 1 and 2). More significant changes of cerebral hemodynamics were found in the medium velocity of blood flow. There was also a significant drop in pulsation index and slight reduction of resistance index (Tables 1 and 2), as it has been shown earlier [33].

Unlike CCAs, MCAs in patients with COPD demonstrate increased peripheral resistance indexes (Table 2).

Brain arteries are frequently considered to be a system comprising interrelated but independent segmental effectors [42, 43]. According to the conducted research, MCAs mostly have vasospastic reactions that are reflected in the increase of both indexes characterizing peripheral resistance level, that is, pulsatility index and resistance index. Also, MCAs in the COPD group 
show lower velocity of blood flow, but they are 2-3 times less pronounced than in CCAs and have significant differences only in the medium velocity parameter. Since the ultimate goal of myogenic response of conductance arteries is to maintain stable blood flow along the whole regional vascular network [44], the discovered reduction in deviations of blood flow velocity in MCAs from the control values is quite logical, unlike in case of the CCA results.

It is important to note that slower blood flow velocity and higher peripheral resistance indexes in the MCAs mostly indicate not the transformation of elastic properties of the vessel but a shift from a dilatatory function of the endothelium to a constricting one which is common for distributional sector of blood circulation in pia matter [13, 42]. Such significant change in pial arteries reaction can be an indicator of endothelial dysfunction resulting from a sequence of biochemical processes triggered by toxic influence of tobacco smoke components and being a product of systemic inflammatory response that suppresses endothelial production of vasodilators, including NO [24].

An important indicator of cerebrovascular hemodynamics is the reaction of small pial and precortical arteries that are extremely sensitive to brain blood flow alterations [42]. Breathholding test (hypercapnic test) and hyperventilation test (hyperoxia test) allow to calculate the indexes of endothelium-dependent reaction of those vessels in terms of their dilatatory and constricting functions, respectively $[45,46]$. The obtained results show an existing imbalance of endothelial vasomotor activity in small pial and cerebral vessels where vasospastic reactions are intensified with unchanged or slightly reduced endothelial dilatation ability of these vessels in patients with smoking-induced COPD (Figure 4) [33]. The value of vascular responsiveness index $(\mathrm{VRI})$ was calculated as: $\mathrm{VRI}=\left(\mathrm{Vps}_{2}-\mathrm{Vps}_{1}\right) / \mathrm{Vps}_{1} \times 100 \%, \mathrm{Vps}_{1}$ is peak systolic velocity in the MCA under investigation and $\mathrm{Vps}_{2}$ is peak systolic velocity in the MCA after

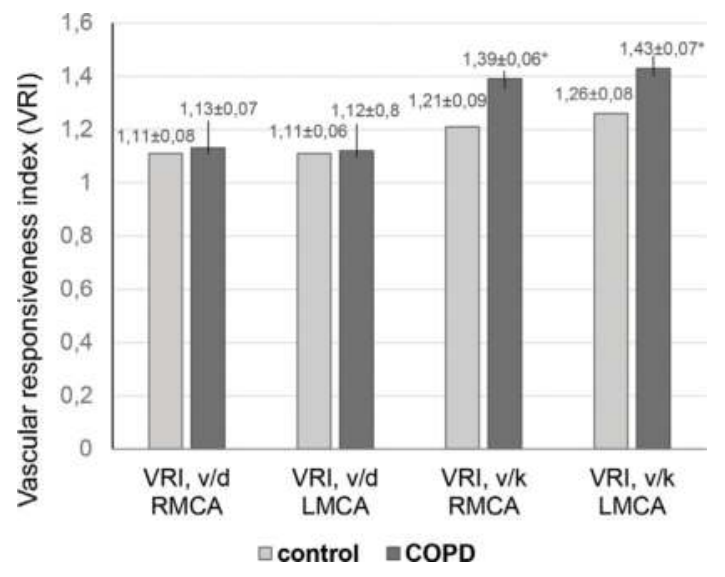

Figure 4. Vascular responsiveness index (VRI) in COPD patients and healthy patients assessed by ultrasound duplex scanning (mean $\pm \mathrm{SD},{ }^{*} \mathrm{p}<0.05$ in comparison with the control group; $\mathrm{t}$-test analysis was used to assess the differences in the values). VRI v/d is cerebral reactivity index to vasodilation, VRI v/c is cerebral reactivity index to vasoconstriction, RMCA is right middle cerebral artery and LMCA is left middle cerebral artery. Explanations are in the text. 
the appropriate tests. One of the hyperoxic vasoconstriction mechanisms can be NO inactivation by superoxide anions resulting from superoxygenation [24, 47]. As a result of those processes, vasorelaxant effect of $\mathrm{NO}$ weakens; perfusion reserve and self-regulation potential of resistance vessels are reduced while the risks of cerebrovascular pathology become higher [48].

At the same time, in the precortical arterioles, the production of vasodilator increases as an adaptive physiological process. It leads to a vasodilatation, increase in diameter of vessels that promotes improvement of brain perfusion as an adaptive mechanism [42]. If this does not happen, the conditions for acute and chronic hemodynamic disorders start to develop. At the moment, enough data have been collected to prove the close connection between one's smoking history and frequency of cerebrovascular events, lacunar strokes, vascular dementia and cognitive deficiency [49-51].

\subsection{Vasomotor function of cerebral vessels in tobacco smoking}

An important feature of cerebral blood circulation is a high level of autonomous self-regulation that provides relative independence and protection for cerebral hemodynamics from shifts in systemic blood circulation. Observation has shown that smoking is an independent risk factor of ischemic stroke for both men and women [50]. We may assume that there is an integrating development mechanism of systemic vascular dysfunction in chronic tobacco smoking that is also responsible for damaging brain vessels. Cerebral blood flow disruption is known to be initiated by the failing self-regulation mechanism, and its vulnerability grows if functional and morphological integrity of endothelium is damaged. Meta-analysis of 22 researches showed that chronic tobacco smoking can double the relative risk of ischemic stroke [50]. Endothelial dysfunction is suggested to be a part of pathological cascade of vascular remodeling influenced by tobacco smoking [52].

In order to study vasomotor activity of endothelium in arteries exposed to chronic tobacco smoke in vivo, many experiments have been designed in rats [53-55]. Considering the similarities between rats and humans in terms of Willis' circle structure and its topography as well as anatomical likeness, the use of these animals is objectively relevant for modeling different pathologies in brain vessels with subsequent extrapolation of the result to humans. Since it is impossible to use non-invasive dopplerography in rats, invasive method had to be used when the rats were injected with vasodilators and vasoconstrictors. Afterwards, the diameter changes in cerebral arteries affected by pharmacological stimuli were studied with magnetic resonance imaging (MRI) brain scanning (Figure 5).

To assess endothelial function of cerebral arteries we used pharmacological tests that proved to be a highly efficient and specific means for studying endothelium-dependent and endotheliumindependent mechanisms of the vasomotor activity regulation. The selected pharmacological agents have well-known action modes and certain points of application allowing to assess the mechanisms of vasomotor reaction development.

The study was conducted on the middle cerebral artery of mature male Wistar rats weighing 180-200 g that were divided into a control group $(n=10)$ and experimental group $(n=10)$, respectively. The animals from the control group were breathing regular atmospheric air, while 


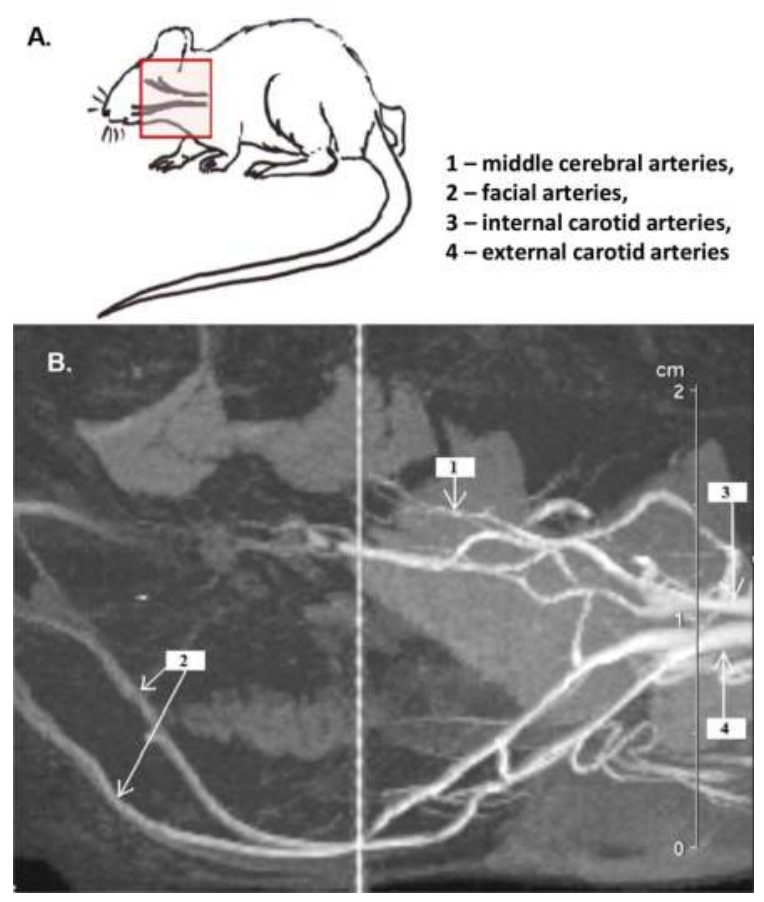

Figure 5. The chart (A) and a MRI tomographic image (B) of the cerebral arteries in the sagittal plane in rats (chronic tobacco smoke model, experimental group). Chart A shows a contour of the tomographic scan area. Arrows in tomographic image point to approximate locations of the measurements of the arteries indicated by numbers: 1: Middle cerebral arteries, 2: Facial arteries, 3: Internal carotid arteries, 4: External carotid arteries. Explanations are in the text.

experimental group was exposed to inhaling tobacco smoke for 6 months to create chronic tobacco smoke model (method by Zheng et al.) [56]. Rats of experimental group were placed in a special chamber for inhalation, where they were exposed to tobacco smoke for $1 \mathrm{~h}$ in the morning and $1 \mathrm{~h}$ in the daytime, 7 days in a week, for 36 weeks. Then, using MRI of the brain, the level of change in the cerebral arteries diameter after pharmacological stimuli was assessed. This method was used for investigating endothelium-dependent vasodilatation (EDVD) after the acetylcholine (ACh) injection, endothelium-independent vasodilatation (EIVD) after the nitroglycerin injection, endothelium-dependent vasoconstriction (EDVC) after the N-monomethyl-Larginine (L-NMLA) injection and endothelium-independent vasoconstriction (EIVC) after the norepinephrine injection. Cerebral vascular reactivity index (CVRI) was used to describe vasomotor function of the endothelium. CVRI was calculated using the formula: CVRI $=(\mathrm{d} 2-\mathrm{d} 1)$ : $(\mathrm{d} 3-\mathrm{d} 1)$, where $\mathrm{d} 1$ is the the initial diameter of the artery, $\mathrm{d} 2$ is diameter of the artery EDVD and $\mathrm{d} 3$ is the diameter of the artery EDVC. Brain MRI was performed on the scanner for experimental studies "PharmaScan US 70/16" (Bruker, Germany).

The study showed vascular dysfunction in cerebral blood circulation of animals chronically exposed to tobacco smoke [57]. Data indicating vasomotor function of brain arteries in rat smokers are presented in Table 3. 


\begin{tabular}{lll}
\hline Descriptor & Control (rats, $\mathbf{N}=10)$ & Tobacco smoking $($ rats, $\mathbf{N}=12)$ \\
\hline EDVD, \% & $+11.89 \pm 0.98$ & $-0.64 \pm 0.02^{*}$ \\
EIDVD, \% & $+17.84 \pm 1.25$ & $+8.64 \pm 0.76^{*}$ \\
EDVC, \% & $-6.31 \pm 0.14$ & $+5.95 \pm 0.34^{*}$ \\
EIDVC, \% & $-4.83 \pm 0.12$ & $-11.2 \pm 1.01^{*}$ \\
\hline
\end{tabular}

Data are presented as mean $\pm \mathrm{SD}$. ${ }^{*} \mathrm{p}<0.05$ (t-test analysis was used to assess the differences in the values) in comparison with the control group. EDVD, endothelium-dependent vasodilation; EIDVD, endothelium-independent vasodilation; EDVC, endothelium-dependent vasoconstriction; EIDVC, endothelium endothelium-independent vasoconstriction; \%, percent change after the appropriate tests.

Table 3. Vasomotor function of cerebral arteries in smoking.

Pharmacological tests caused expected endothelium-dependent and endothelium-independent vasodilation in healthy rats proving that NO synthase and GC mechanisms of vascular endothelium dilation remained intact [57].

At the same time, our results showed significant differences in vasomotor reactions of rats exposed to tobacco smoking. ACh stimulates eNOS causing NO secretion that results in pronounced EDVD [58]. Our results showed that the control group of rats exhibited an expected, sufficient level of EDVD in their brain vessels. Furthermore, arterial diameter increased by more than $10 \%$ of the original level in healthy rats indicating that the Enos-mediated mechanism of vasodilation remained intact (Table 3 ).

Alternatively, the group of smokers had pathological vasospastic reactions after ACh administration (Table 3). The reason might be related to functional damage of vascular endothelium. Some experiments showed that chronic exposure to tobacco smoke causes NO deficiency and weaker activity of eNOS [59, 60]. Based on previous mechanistic reports [53-55], we can assume that there is an NO deficiency and lower level of endothelial eNOS activity in our model of tobacco smoking that indicates substantial damage of eNOS mechanism and thus impaired vasodilation.

Apart from the eNOS mechanism of vasodilation, there is also another one involving GC. NO molecule is a highly active radical due to its unpaired electron. Its chemical properties allow it to access vascular myocytes and activate intracellular GC without any receptors. As a result, the cell concentration of cGMP becomes higher, and smooth muscle cells relax [61, 62]. GC mechanism of vasodilation was studied by injecting rats with nitroglycerin as the NO donor. The control group of rats had an expected level of EIDVD induced by nitroglycerin. In addition, arterial diameter increases by more than $15 \%$ of the original level indicates that GC endothelium-independent mechanism of vasodilation in healthy rats remained intact [63]. Chronic smokers' group had insufficient vasodilation after the same stimulation that indicates damages in both eNOS and GC mechanisms of vasodilation in animal smokers. Some authors believe that weaker response of vascular smooth muscle cells to nitrovasodilators might be initiated by hypoxia that exists in long-term smoking [52, 64-66].

Analysis of the constricting section in the smokers' group shows pathological vasodilation in response to L-NMMA constrictor administration and pronounced constriction after norepinephrine 
injection [57]. L-NMMA test allows us to evaluate consistency of adrenergic mechanisms of vascular tone regulation and endothelium-dependent vasoconstriction [57]. L-NMMA directly inhibits eNOS and indirectly inhibits inducible NOS (iNOS). Its injection helps to reduce NO production in endothelial cells and abolishes the NO-dependent dilation of vessels $[67,68]$.

At any specific time, vascular tone is defined by the balance of constricting and dilating influence on vascular smooth muscle cells. VRI of vasodilation in the smokers' group was 15 times lower than required (VRI for the control group is $1.88 \pm 0.11$; VRI for the smokers' group is $0.12 \pm 0.08 ; \mathrm{p}<0.001)$ that indicates a significant damage of endothelial vasomotor function due to predominant pathological constricting reactions (Figure 6).

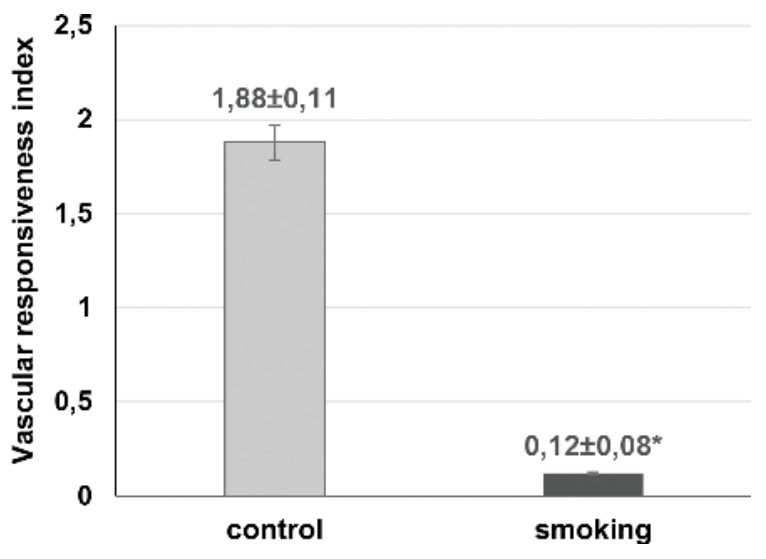

Figure 6. Vascular responsiveness index (VRI) of cerebral arteries in rats obtained by MRI scanning (chronic tobacco smoke model, experimental group, results are presented as mean $\pm \mathrm{SD},{ }^{*} \mathrm{p}<0.05$ in comparison with the control group; t-test analysis was used to assess the differences in the values).

\section{Conclusion}

Endothelium initiates and modulates the main pathomorphological processes of chronic respiratory diseases. In particular, endothelium activation is an important factor of initiation, development and persistence of inflammation and vessels and tissue remodeling; it contributes to lymph circulation dysfunction and development of systemic effects. Endothelial cells of different vessels are morphologically and functionally oriented toward optimal regulation of organs' blood supply by synthesizing and releasing locally acting mediators. Pathology of endothelial cells can develop selectively: the cells are sensitive to hypoxia, tobacco smoke influence, products of inflammatory response, peroxidation, ischemic disorders, swelling and so on. Vessel remodeling usually starts as adaptation to hemodynamic changes or activity of tissue and circulating humoral factors. Long-term adaptation is replaced by vessel structure deterioration as a response to damaging factors, including toxic components of tobacco smoke and metabolites and atherogenic factors or changes of hemodynamic load. Cognitive dysfunction in cases of chronic nicotine-associated 
diseases is recognized by the majority of medical experts as one of the systemic symptoms of such diseases and a big medical and socioeconomic challenge. Studying the peculiarities of endothelium dysfunction caused by chronic exposure to tobacco smoke is relevant for finding a way of treating progressing cognitive deficiency and developing personalized methods of preventing acute vascular events.

\section{Author details}

Vera Nevzorova, Tatiana Brodskaya* and Natalia Zakharchuk

*Address all correspondence to: brodskaya@mail.ru

Pacific State Medical University, Vladivostok, Russia

\section{References}

[1] http://www.who.int/mediacentre/factsheets/fs339/en/

[2] How Tobacco Smoke Causes Disease: The Biology and Behavioral Basis for SmokingAttributable Disease: A Report of the Surgeon General. Atlanta (GA): Centers for Disease Control and Prevention (US); 2010. 6, Cardiovascular Diseases. PMID: 21452462. Available from: https://www.ncbi.nlm.nih.gov/books/NBK53012/

[3] Kukovetz WR, Holzmann S, Romanin C. Mechanism of vasodilation by nitrates: Role of cyclic GMP. Cardiology 1987;74(Suppl 1):12-19. PMID: 2886220

[4] Benowitz NL. Pharmacology of nicotine: Addiction, smoking-induced disease, and therapeutics. Annual Review of Pharmacology and Toxicology. 2009;49:57-71. DOI: 10.1146/ annurev.pharmtox.48.113006.094742

[5] Rabinoff M, Caskey N, Rissling A, Park C. Pharmacological and chemical effects of cigarette additives. American Journal of Public Health. 2007;97(11):1981-1991. DOI: 10.2105/ AJPH.2005.078014

[6] Baluk P, Tammela T, Ator E, Lyubynska N, Achen MG, Hicklin DJ, Jeltsch M, Petrova TV, Pytowski B, Stacker SA, Ylä-Herttuala S, Jackson DG, Alitalo K, McDonald DM. Pathogenesis of persistent lymphatic vessel hyperplasia in chronic airway inflammation. Journal of Clinical Investigation. 2005;115:247-257. DOI: 10.1172/JCI22037

[7] Brodskaya TA, Nevzorova VA, Geltser BI, Motkina EV. Endothelial dysfunction and respiratory disease. Terapevticheskij arkhiv. 2007;3:76-84. PMID: 17526203

[8] Harkness LM, Ashton AW, Burgess JK. Asthma is not only an airway disease, but also a vascular disease. Pharmacology and Therapeutics. 2015;148:17-33. DOI: 10.1016/j.pharmthera. 2014.11.010 
[9] Pretnar-Oblak J. Cerebral endothelial function determined by cerebrovascular reactivity to L-arginine. BioMed Research International. 2014;2014:8. DOI: 10.1155/2014/601515

[10] Goldenberg NM, Kuebler WM. Endothelial cell regulation of pulmonary vascular tone, inflammation, and coagulation. Comprehensive Physiology. 2015;5(2):531-559. DOI: 10.1002/ cphy.c140024

[11] Brodskaya TA, Geltser BI, Nevzorova VA. Arterial Stiffness and Respiratory Diseases (Pathophysiological Mechanisms and Clinical Significance). Vladivostok: Dalnauka; 2008. 248 p. ISBN 978-5-8044-0928-0

[12] Vukic Dugac A, Ruzic A, Samarzija M, Badovinac S, Kehler T, Jakopovic M. Persistent endothelial dysfunction turns the frequent exacerbator COPD from respiratory disorder into a progressive pulmonary and systemic vascular disease. Medical Hypotheses. 2015; 84(2):155-158. DOI: 10.1016/j.mehy.2014.11.017

[13] Chertok VM, Kotsyuba AE. Endothelial (intimal) mechanism of cerebral hemodynamics regulation: Changing views. Pacific Medical Journal. 2012;2:17-26

[14] Geltser BI, Brodskaya TA, Kotelnikov VN, Agafonova IG, Lukyanov PA. Endothelial dysfunction of cerebral and major arteries during chronic obstructive disease. Experimental Biology and Medicine. 2007;144(6):768-771. DOI: 10.1007/s10517-007-0427-x

[15] Paulson OB, Strandgaard S, Edvinsson L. Cerebral autoregulation. Cerebrovascular and Brain Metabolism Reviews. 1990;2:161-192. PMID: 2201348

[16] Dodd J, Getov S, Jones P. Cognitive function in COPD. The European Respiratory Journal. 2010;35(4):913-922. DOI: 10.1183/09031936.00125109

[17] Singh B, Mielke M, Parsaik A, Cha R, Roberts R, Scanlon P, Geda Y, Christianson T, Pankratz S, Petersen R. A prospective study of chronic obstructive pulmonary disease and the risk for mild cognitive impairment. JAMA Neurology. 2014 May;71(5):581-588. DOI: 10.1001/jamaneurol.2014.94

[18] Krebs R, Tikkanen JM, Nykänen AI, Wood J, Jeltsch M, Ylä-Herttuala S, Koskinen PK, Lemström KB. Dual role of vascular endothelial growth factor in experimental obliterativ bronchiolitis. American Journal of Respiratory and Critical Care Medicine. 2005;171:14211429. DOI: $10.1164 / \mathrm{rccm} .200408-10010 \mathrm{C}$

[19] Nevzorova VA, Brodskaya TA, Golotina OV, Shekunova OI. Cardiovascular Dysfunction in Chronic Obstructive Pulmonary Disease and Ischemic Heart Disease (Functional Metabolic Parallels). Vladivostok: Dalnauka; 2015. 160 p. ISBN 978-5-8044-1548-9

[20] Van Lieshout RJ, Macqueen G. Psychological factors in asthma. Allergy, Asthma and Clinical Immunology. 2008;4(1):12-28. DOI: 10.1186/1710-1492-4-1-12

[21] Puranik R, Celermajer DS. Smoking and endothelial function. Progress in Cardiovascular Diseases. 2003;45:443-458. DOI: 10.1053/pcad.2003.YPCAD13

[22] Mahmud A, Feely J. Effect of smoking on arterial stiffness and pulse pressure. Hypertension. 2003;41(1):183-187. PMID: 12511550 
[23] Barnoya J, Glantz SA. Cardiovascular effects of secondhand smoke: Nearly as large as smoking. Circulation. 2005;111(20):2684-2698. DOI: 10.1161/CIRCULATIONAHA.104.492215

[24] Guo X, Oldham MJ, Kleinman MT, Phalen RF, Kassab GS. Effect of cigarette smoking on nitric oxide, structural, and mechanical properties of mouse arteries. American Journal of Physiology. Heart and Circulatory Physiology. 2006;291(5):2354-2361. DOI: 10.1152/ajp heart.00376.2006

[25] Nevzorova V, Vakhrusheva S, Tilik T, Surovenko T, Brodskaya T, Isaeva M. Polymorphism of GSTP1 and EPHX1 genes in smokers and patients with I and II stages of chronic obstructive pulmonary disease. European Respiratory Journal. 2012;40(S56):776. DOI: 10.1183/13993003.2012.PA776

[26] Jaldin RG, Castardelli É, Perobelli JE, Yoshida WB, de Castro Rodrigues A, Sequeira JL, Paiva SA. Morphologic and biomechanical changes of thoracic and abdominal aorta in a rat model of cigarette smoke exposure. Annals of Vascular Surgery. 2013;27(6):791-800. DOI: 10.1016/j.avsg.2013.03.002

[27] Brady AR, Thompson SG, Fowkes FGR, Greenhalgh RM, Powell JT, UK Small Aneurysm Trial Participants. Abdominal aortic aneurysm expansion: Risk factors and time intervals for surveillance. Circulation. 2004;110(1):16-21. DOI: 10.1161/01.CIR.0000133279.07468.9F

[28] Wilmink TBM, Quick CRG, Day NE. The association between cigarette smoking and abdominal aortic aneurysms. Journal of Vascular Surgery. 1999;30(6):1099-1105

[29] Hunninghake DB. Cardiovascular disease in chronic obstructive pulmonary disease. Proceedings of the American Thoracic Society. 2005;2(1):44-49. DOI: 10.1513/pats.200410-050SF

[30] Sin DD, Man SFP. Chronic obstructive pulmonary disease as a risk factor for cardiovascular morbidity and mortality. The Proceedings of the American Thoracic Society. 2005;2: 8-11. DOI: 10.1513/pats.200404-032MS

[31] Michiel JB, Peter JK, Albert H, Jacqueline W, Monique B. Transcranial doppler hemodynamic parameters and risk of stroke: The Rotterdam study. Stroke. 2007;38:2453-2458. DOI: 10.1161/STROKEAHA.107.483073

[32] Grant EG, Benson CB, Moneta GL, Alexandrov AV, Baker JD, Bluth EI, Carroll BA, Eliasziw M, Gocke J, Hertzberg BS, Katanick S, Needleman L, Pellerito J, Polak JF, Rholl KS, Wooster DL, Zierler RE. Carotid artery stenosis: Gray-scale and Doppler US diagnosis - Society of Radiologists in ultrasound consensus conference. Radiology. 2003;229:340346. DOI: 10.1148/radiol.2292030516

[33] Zakharchuk NV, Nevzorova VA, Chertok VM, Sarafanova NS. Effects of chronic tabacco smoking on the cerebral blood flow. Zhurnal Nevrologii i Psikhiatrii Imeni S.S. Korsakova. 2017;117(2):124-129. DOI: 10.17116/jnevro201711721124-129

[34] Barr RG, Ahmed FS, Carr JJ, Hoffman EA, Jiang R, Kawut SM, Watson K. Subclinical atherosclerosis, airflow obstruction and emphysema: The MESA lung study. The European Respiratory Journal. 2012;39:846-854. DOI: 10.1183/09031936.00165410 
[35] Iwamoto H, Yokoyama A, Kitahara Y, Ishikawa N, Haruta Y, Yamane K, Hattori N, Hara $\mathrm{H}$, Kohno N. Airflow limitation in smokers is associated with subclinical atherosclerosis. American Journal of Respiratory and Critical Care Medicine. 2009;179:35-40. DOI: 10.1164/ rccm.200804-560OC

[36] Lahousse L, Bouwhuijsen Q, Loth D, Joos G, Hofman A, Witteman J, Lugt A, Brusselle G, Stricker B. Chronic obstructive pulmonary disease and lipid core carotid artery plaques in the elderly. The Rotterdam study. American Journal of Respiratory and Critical Care Medicine. 2013;187(1):58-64. DOI: 10.1164/rccm.201206-1046OC

[37] Chindhi S, Thakur S, Sarkar M, Negi PC. Subclinical atherosclerotic vascular disease in chronic obstructive pulmonary disease: Prospective hospital-based case control study. Lung India. 2015;32(2):137-141. DOI: 10.4103/0970-2113.152624

[38] Ambrosino P, Lupoli R, Cafaro G, Iervolino S, Carone M, Pappone N, Di Minno MND. Subclinical carotid atherosclerosis in patients with chronic obstructive pulmonary disease: A meta-analysis of literature studies. Annals of Medicine. 2017;49(6):513-524. DOI: 10.1080/07853890.2017.1311022

[39] Suwa T, Hogg JC, Quinlan KB, Ohgami A, Vincent R, van Eeden SF. Particulate air pollution induces progression of atherosclerosis. Journal of the American College of Cardiology. 2002;39:935-942. PMID: 11897432

[40] Kool M, Hoeks A, Struijker Boudier H, Reneman R, Van Bortel L. Short- and long-term effects of smoking on arterial wall properties in habitual smokers. Journal of the American College of Cardiology. 1993;22:1881-1886. DOI: 10.1016/0735-1097(93)90773-T

[41] Macnee W, Maclay J, McAllister D. Cardiovascular injury and repair in chronic obstructive pulmonary disease. Proceedings of the American Thoracic Society. 2008;5(8):824-833. DOI: 10.1513/pats.200807-071TH

[42] Chertok VM, Kotsyuba AE. Age-associated characteristics of vasomotor regulation of the pia mater arteries in rats. Bulletin of Experimental Biology and Medicine. 2010;149(3):364368. DOI: 10.1007/s10517-010-0947-7

[43] Zakharchuk NV, Chertok VM, Nevzorova VA, Gonchar EY. Effect of chronic tobacco smoking on the tachykinin receptors distribution in the rats pial arteries. Bulletin of Experimental Biology and Medicine. 2017;3:290-293

[44] Alexandrin $\mathrm{V}$, Alexandroff $\mathrm{P}$. The model of a myogenic response of pial arterioles. Regional Haemodynamics and Microcirculation. 2003;1(5):73-76

[45] Moreton FC, Dani KA, Goutcher C, O'Hare K, Muir KW. Respiratory challenge MRI: Practical aspects. NeuroImage: Clinical. 2016;11:667-677. DOI: 10.1016/j.nicl.2016.05.003

[46] Thomas BP, Liu P, Aslan S, King KS, van Osch MJ, Lu H. Physiologic underpinnings of negative BOLD cerebrovascular reactivity in brain ventricles. NeuroImage. 2013;83:505512. DOI: 10.1016/j.neuroimage.2013.07.005 
[47] Demchenko I, Moskvin A, Zhiliaev S, Alekseeva O, Postnikova T, Krivchenko A. Effect of nitric oxide/endothelin interaction on hyperoxic vasoconstriction. Russian Journal of Physiology. 2011;97(6):609-618. PMID: 21874873

[48] Gorshkova O, Lensman M, Artem'eva A, Dvoretsky D. Dynamics of pial vessels reactivity after brief cerebral ischemia. Journal of Regional Haemodynamics and Microcirculation. 2015;14(1):74-78

[49] Kurth T, Kase C, Berger K, Schaeffner E, Buring J, Gaziano J. Smoking and the risk of hemorrhagic stroke in men. Stroke. 2003;34:1151-1155. DOI: 10.1161/01.STR.0000065200.93070.32

[50] Shinton R, Beevers G. Meta-analysis of relation between cigarette smoking and stroke. BMJ. 1989;298:789-794. DOI: 10.1136/bmj.298.6676.789

[51] Mazzone P, Tierney W, Hossain M, Puvenna V, Janigro D, Cucullo L. Pathophysiological impact of cigarette smoke exposure on the cerebrovascular system with a focus on the blood-brain barrier: Expanding the awareness of smoking toxicity in an underappreciated area. International Journal of Environmental Research and Public Health. 2010;7:41114126. DOI: 10.3390/ijerph7124111

[52] Papamichael CM, Aznaouridis KA, Stamatelopoulos KS, Karatzis EN, Protogerou AD, Papaioannou TG, Lekakis JP, Mavrikakis ME. Endothelial dysfunction and type of cigarette smoked: The impact of 'light' versus regular cigarette smoking. Vascular Medicine. 2004;9:103-105. DOI: 10.1191/1358863x04vm529oa

[53] Cao L, Zhang Y, Cao YX, Edvinsson L, Xu CB. Cigarette smoke upregulates rat coronary artery endothelin receptors in vivo. PLoS One. 2012;7(3):e33008. DOI: 10.1371/journal. pone.0033008

[54] Xu CB, Lei Y, Chen Q, Pehrson C, Larsson L, Edvinsson L. Cigarette smoke extracts promote vascular smooth muscle cell proliferation and enhances contractile responses in the vasculature and airway. Basic \& Clinical Pharmacology \& Toxicology. 2010;107(6):940948. DOI: 10.1111/j.1742-7843.2010.00610.x

[55] Rahman MM, Elmi S, Chang TK, Bai N, Sallam NA, Lemos VS, Moien-Afshari F, Laher I. Increased vascular contractility in isolated vessels from cigarette smoking rats is mediated by basal endothelin release. Vascular Pharmacology. 2007;46:35-42. DOI: 10.1016/j. vph.2006.06.006

[56] Zheng H, Liu Y, Huang T, Fang Z, Li G, He S. Development and characterization of a rat model of chronic obstructive pulmonary disease (COPD) induced by sidestream cigarette smoke. Toxicology Letters. 2009;189(3):225-234. DOI: 10.1016/j.toxlet.2009.06.850

[57] Nevzorova VA, Zakharchuk NV, Agafonova IG, Belushkina TR, Gilifanov EA. Endotheliumdependent and endothelium-independent cerebral vessels reactions in a chronic smoking model. International Journal of Biomedicine. 2011;2:103-107

[58] Furchgott RF, Zawadzki JV. The obligatory role of endothelial cells in the relaxation of arterial smooth muscle by acetylcholine. Nature. 1980;288:373-376. DOI: 10.1038/288373a0 
[59] Zeiher AM, Schachinger V, Minnes J. Long-term cigarette smoking impairs endothelium independent coronary arterial vasodilator function. Circulation. 1995;92:1094-1100. PMID: 7648652

[60] Celermajer DS, Adams MR, Clarkson P, Robinson J, McCredie R, Donald A, Deanfield JE. Passive smoking and impared endothelium-dependent arterial dilatation in healthy young adults. The New England Journal of Medicine. 1996;334(3):150-154. DOI: 10.1056/ NEJM199601183340303

[61] Vane JR, Anggård EE, Botting RM. Regulatory functions of the vascular endothelium. New England Journal of Medicine. 1990;323(1):27-36. DOI: 10.1056/NEJM199007053230106

[62] Busse R, Mulsch A, Fleming I, Hecker M. Mechanisms of nitric oxide release from the vascular endothelium. Circulation. 1993;87(Suppl.V):18-26

[63] Marin J, Rodriges-Martinex MA. Role of vascular nitric oxide in physiological and pathological conditions. Pharmacology \& Therapeutics. 1997;75(2):111-134. PMID: 9428001

[64] Celermajer DS, Sorensen KE, Georgakopoulos D, Bull C, Thomas O, Robinson J, Deanfield JE. Cigarette smoking is associated with dose-related and potentially reversible impairment of endothelium-dependent dilation in healthy young adults. Circulation. 1993;88(5 Pt 1):2149-2155. PMID: 8222109

[65] Dupuy PM, Lançon JP, Françoise M, Frostell CG. Inhaled cigarette smoke selectively reverses human hypoxic vasoconstriction. Intensive Care Medicine. 1995;21(11):941-944. PMID: 8636528

[66] Ferrer E, Peinado VI, Castañeda J, Prieto-Lloret J, Olea E, González-Martín MC, VegaAgapito MV, Díez M, Domínguez-Fandos D, Obeso A, González C, Barberà JA. Effects of cigarette smoke and hypoxia on pulmonary circulation in the guinea pig. The European Respiratory Journal. 2011 Sep;38(3):617-627. DOI: 10.1183/09031936.00105110

[67] Repina N, Brodskaya T, Nevzorova V. Aortic stiffness in European ethnicity persons with arterial hypertension related to smoking. Journal of Hypertension. 2016;34(S1):e147. DOI: 10.1097/01.hjh.0000500283.43262.ea

[68] Miyazaki H, Matsuoka H, Cooke JP, Usui M, Ueda S, Okuda S, Imaizumi T. Endogenous nitric oxide synthase inhibitor: A novel marker of atherosclerosis. Circulation. 1999;99(9): 1141-1146. PMID: 10069780 
